double-entry table giving the range in yards as respondent. An auxiliary table gives the error in the range in yards consequent upon an error of one foot in the height for each of the tabulated angles.

It appears that one of the standard methods for finding the range of an enemy ship required the measurement of the angle in the vertical plane between the waterline of the enemy ship and a point vertically below the observer who was required to be perched high above the deck on the cross-trees or a yard-arm. Ryder's table was designed to facilitate finding ranges by this method, a measured angle in this circumstance being used as argument direct, no dip correction being necessary. The difficulties that ranged themselves in opposition to this latter method must have prevented its ever having been of service.

\title{
REFERENCES
}

1 Sayers, P. H. (1968). Distance by vertical angle. This Journal, $21,83$.

2 Thompson, P. A. (1969). Distance-off by angle of depression. This Journal, 22, 141 .

3 Cotter, C. H. (1962). The Master and His Ship, London.

4 Lecky, S. T. S. (1890). The Danger Angle and Off-Shore Distance Tables, London.

5 Moxly, S. H. S. (1941). Coostal Tables for Use in Sight of Land, Glasgow.

6 Ryder, A. P. (Ist Edn 1845, 2nd Edn 1854, 3 rd Edn 1858). Methods of Ascertaining the Distance from Ships at Sea. London.

\section{A Note on Research Using Computers}

\section{A. Robinson}

LATELY there have been a number of articles and discussions in the Journal involving the use of computer programs to solve navigational problems. As one often involved in complex programming systems, I have some strong views on the subject. We are not an institution of programmers, and the few of us who have some programming knowledge, a very useful asset, are usually limited to one or possibly two languages. I would doubt if many people who could follow B. J. Moss's aLgol could also follow R. J. Turner's Fortran. Thus it seems strange that authors should go to the trouble of publishing the routines by which they do their calculations. After all, most of us are only interested in the method of attack and the answers rather than computer techniques.

In an article in the Forum, J. S. McKenzie criticizes Turner's forrran writing ability and then proceeds to complain as to his choice of language. True Turner's programs are not particularly efficient and obviously written with little consideration of speed or core requirements but perhaps McKenzie is a little harsh. Fully polishing programs is not really necessary when it is the answers that are really sought. After all, when the G.P. computer becomes commonplace, it will be practised programmers who will write the programs from specifications developed by the researchers into these navigational problems. It is the professional programmers who will take into account the speed and core requirements of the machine chosen for the purpose. It is the investigators in navigation who will provide the necessary means of solution. 


\section{REFEREN CES}

Turner, R. J. (1970). Rhumb-line sailing with a computer. This Journal, 23, 233. Moss, B. J. (1969). Exploration with a computer on rhumb-line sailing. This Journal, 22, 242.

McKenzie, J. S. (197 I). Rhumb-line failings. This Journal, 24, 123.

\section{'NAVIGATION'}

Navigation (Paris), the quarterly Journal of the French Institute of Navigation, is available to Members of the Institute at the preferential subscription rate of £2.00 per annum. Subscriptions should be addressed to the Institute office in London.

The July 197 I number includes a paper by Van Etten on low frequency and very low frequency navigation systems; a description of 'Navstar'; an appreciation by Manuali of the usefulness of satellites for civil aviation and merchant marine navigation; a paper on time routes under sail; an article on Arab navigation in the Indian Ocean; some notes on weather routing; and an article on the discovery of the Jacob's Staff.

In addition there is, as usual, a record of navigational interest, reviews and correspondence. 